\title{
ANÁLISE COMPARATIVA DA RADIODENSIDADE DE CIMENTOS RESINOSOS UTILIZANDO UM SISTEMA DE RADIOGRAFIA DIGITAL
}

Giovana Mongruel GOMES, Abraham Lincoln CALIXTO

Os cimentos resinosos são materiais utilizados para cimentação de próteses parciais fixas e pinos intra-radiculares, sendo sua radiodensidade fundamental para detecção de excessos proximais e para acompanhamento longitudinal da presença de cárie recorrente. Avaliou-se a radiodensidade de três cimentos resinosos: GI-CEMENT POST-ÂNGELUS ${ }^{\circledR}$ (quimicamente ativado), GII-RelyX ARC-3MESP (polimerização dual) e GIII-Variolink II-Ivoclar/Vivadent (fotoativado). Confeccionou-se 5 corpos-de-prova para cada grupo, padronizados com o auxílio de uma matriz de teflon ( $8 \mathrm{~mm}$ de diâmetro e 2 $\mathrm{mm}$ de espessura). Foi empregado o Sistema Intra-oral de Raio-x Digital (GNATUS) e o software Cygnus Imaging ${ }^{\circledR}$ para as tomadas radiográficas. Após a captura da imagem a radiodensidade foi avaliada por um sistema digital de imagens, determinando níveis de cinza, mensurados com o software Image $\mathrm{Too}^{\circledR}$. O resultado foi obtido por mensuração de pixels contidos nas imagens. Os valores médios e o desvio padrão em porcentagens (\%) de branco e preto encontrados para o Gl- 48,94\% e 51,06\% $\pm 3,16$, GII- 60,22\% e $39,78 \% \pm 3,86$ e GIII- $69,36 \%$ e $30,64 \% \pm 5,32$. Concluiu-se que o GIII apresentou maior radiodensidade que os GIl e o Gl; e que a avaliação da radiopacidade pelo sistema digital é uma alternativa rápida, segura e de fácil execução. 